This item was submitted to Loughborough's Research Repository by the author.

Items in Figshare are protected by copyright, with all rights reserved, unless otherwise indicated.

\title{
The role of actor associations in understanding the implementation of Lean thinking in healthcare
}

PLEASE CITE THE PUBLISHED VERSION

http://dx.doi.org/10.1108/01443571111104755

PUBLISHER

(C) Emerald

VERSION

AM (Accepted Manuscript)

\section{PUBLISHER STATEMENT}

This work is made available according to the conditions of the Creative Commons Attribution-NonCommercialNoDerivatives 4.0 International (CC BY-NC-ND 4.0) licence. Full details of this licence are available at: https://creativecommons.org/licenses/by-nc-nd/4.0/

\section{LICENCE}

CC BY-NC-ND 4.0

\section{REPOSITORY RECORD}

Papadopoulos, Thanos, Zoe J. Radnor, and Yasmin Merali. 2019. "The Role of Actor Associations in Understanding the Implementation of Lean Thinking in Healthcare". figshare.

https://hdl.handle.net/2134/15860. 
The Role of Actor Associations in Understanding the Implementation of Lean Thinking in Healthcare

\begin{abstract}
Purpose - The importance of networks in effecting the outcomes of change processes is wellestablished in the literature. Whilst extant literature focuses predominantly on the structural properties of networks, our purpose is to explore the dynamics of network emergence that give rise to the outcomes of process improvement interventions. Through the use of ActorNetwork Theory (ANT) we explore the dynamics in the implementation of a process improvement methodology in the complex organisational setting of a UK National Health Service Trust. The paper illustrates the utility of ANT in articulating the dynamic nature of networks underpinning socio-technical change, and our analysis provides insights for the management process change initiatives.
\end{abstract}

Design/methodology/approach - This is a rich qualitative study in the Pathology Unit of a UK National Health Service Trust, using ANT as the theoretical lens for tracking the emergence and transformation of networks of individuals over the course of a management intervention to promote "Lean thinking” for process performance improvements.

Findings - ANT is useful for explicitly tracking how organisational players shift their positions and network allegiances over time, and for identifying objects and actions that are effective in engaging individuals in networks which enable transition to a Lean process. It is important to attend to the dynamics of the process of change and devise appropriate timely interventions enabling actors to shift their own positions towards a desired outcome.

Research limitations/implications - We make the case for using theoretical frameworks developed outside the operations management to develop insights for designing process interventions.

Originality/value - By understanding the role of shifting networks managers can use timely interventions during the process implementation to facilitate the transition to Lean processes: e.g. using demonstrable senior leadership commitment and visual communication.

Paper Type - Research paper.

Keywords: Actor associations, process improvement interventions, Lean Thinking, ActorNetwork Theory 


\section{The Role of Actor Associations in Understanding the Implementation of Lean Thinking in Healthcare}

\section{Introduction}

Over the past decade the UK National Health Service (NHS) sector has been characterised by a series of process improvement programmes aimed at improving the efficiency and effectiveness of the delivery of health care. Whilst significant resources have been committed to these programmes and along with the introduction of change agents and information technology for the development of clinical pathways and support services, our understanding of their implementation is still limited (Savitz et al., 2000). Recent literature on the implementation of change programmes in the NHS highlights the importance of networks in effecting and affecting the outcomes of these programmes (Papadopoulos and Merali, 2008; 2009) and calls for more theoretical and empirical work to examine the role of networks in this context (Bevir and Richards, 2009; Greenhalgh et al., 2004; Rhodes, 2007). This paper responds to that call by using Actor-Network Theory (ANT) as a lens for exploring the dynamics of network emergence that give rise to the outcomes of a process improvement intervention drawing on Lean thinking in the complex organisational setting of a UK NHS Trust.

The choice of Lean thinking as the basis for the process improvement intervention in the Trust is largely attributable to the general popularity of Lean approaches in the NHS (Brandao de Souza, 2009; Radnor, 2010). However, although the use of “Lean” as a label for interventions in the NHS is widespread, the interpretation of this label by the various actors involved in, or affected by, the interventions is varied. This equivocality resonates with the wider challenges of transferring the practice of lean process improvement from its origins in manufacturing to the service-oriented setting of the NHS. By examining the emerging associations (dynamics) between the heterogeneous actors, who influence the meaning of Lean and shape the trajectory and results of the implementation process in the Trust, this paper aims to explore some of the reasons why implementing process improvement in the health services remains problematic and complex. It is important to note that the Trust was not implementing the entire methodology of Lean process improvement; rather it was using some techniques associated with Lean thinking in order to improve the efficiency of selected processes. In essence this paper presents the use of ANT to explore the dynamics in the 
implementation of a process improvement approach methodology which itself originates from a different context. Our use of ANT resonates with Taylor and Taylor's (2009) endorsement of alternative methods from outside the OM field to explore new dimensions of the impact of Operations Management.

ANT constitutes a powerful lens for making sense of the implementation of complex phenomena which have organisational and technical dimensions (Callon, 1986; Czarniawska, 1997; Latour, 1986; 2005; Law, 1992; Law and Hassard, 1999). We propose two reasons why ANT provides additional value in explaining process interventions predicated on Lean thinking. Firstly, ANT offers a perspective for exploring how the social, political and cognitive dimensions of the associations between the different actors emerge and, therefore, shape the meaning and the outcome of Lean concepts, as well as dynamically maintaining temporary coherence/consensus between the actors entailed in the Lean deployment process. Secondly, ANT takes into consideration the role of non-human entities in the analysis, thereby allowing for a more explicit analysis of the enabling or the restricting role of management tools; for instance, visual tools such as process maps, questionnaires and communication boards. Therefore, the application of ANT is a lens through which a number of implications related to the deployment of interventions based on Lean thinking which are not apparent within the current Lean or process improvement literature can be explored.

The paper is organised as follows. The overview of Lean thinking in healthcare in the next section is followed by an introduction to the concepts of ANT in Section 3. Section 4 outlines the research method for the case study presented in Section 5. The implications of our analysis are discussed in Section 6, and our conclusions are presented in Section 7.

\section{Lean Thinking in healthcare}

The concept of Lean (Womack et al., 1990) has gained widespread attention, both in academic literature and in practice. In manufacturing, Lean constitutes an innovative philosophy which aims at using fewer resources compared to traditional mass production systems, focusing instead on general principles at a strategic level and tools and techniques at an operational level (Hines et al., 2004; Shah and Ward, 2003). The principles of Lean are based on an underlying assumption that organisations are made up of processes and are linked to the concept of value, waste reduction and continuous improvement (kaizen) through an ever-repeating process (Womack and Jones, 1996). It is often stated that at the core of the success of Lean implementation are changes in behaviour, culture and mindsets, as it requires 
a strategy for the orchestration of both tools/techniques and cultural changes (Hines et al., 2008; Shah and Ward, 2007; Spear and Bowen, 1999).

Lean has been embraced across public services especially since 2005, with Healthcare, Central Government and Local Government organisations embracing and implementing 'Lean': in a recent literature review focusing on the use of process improvement methodologies in the public sector, $51 \%$ of publications focused on Lean, and $35 \%$ on health services (Radnor, 2010). Lean projects in healthcare have become widespread: in existing literature on Lean healthcare applications and reports the USA predominates (57\%), with the UK growing at a fast pace (29\%), followed by Australia at 4\% (Brandao de Souza, 2009). Approaches based on Lean principles in Healthcare settings, particularly in hospitals, are reported to have a significant impact on quality, cost and time and satisfaction of both staff and customers. Results reported have been in terms of tangible outputs such as reduction of processing or waiting time, increase in quality through a reduction of errors, and reduction in costs (Silvester et al., 2004), as well as intangibles such as increased employee motivation and satisfaction, and increased customer satisfaction (Radnor and Boaden, 2008). However it is important to note that many of these implementations have been confined to a single process or ward rather than a complete patient pathway.

Although Lean is increasingly prevalent, the literature suggests that healthcare organisations are implementing Lean through the use of simple tools and techniques through small enclosed projects, creating "pockets of best practice” (Brandao de Souza, 2009; Radnor, 2010). Virginia Mason Medical Centre in Seattle (USA), Flinders in Australia and the Royal Bolton NHS Foundation Trust in the UK have become celebrated examples of Lean implementation in healthcare settings, although Spear (2005) asserts that "in healthcare, no organization has fully institutionalized to Toyota's level the ability to design work as experiments, improve work through experiments, share the resulting knowledge through collaborative experimentation and develop people as experimentalists” (p. 91).

Table 1 illustrates some examples of the implementation of Lean in healthcare indicating various approaches and tools that have been used, including Lean production, flow, Rapid Improvement Events (RIE) ${ }^{1}$, and process mapping in hospitals to improve emergency care services, intensive care units and operating units and to reduce waiting times (Silvester et al.., 2004). Table 1 also illustrates some typical tangible and intangible reported benefits of Lean implementation.

\footnotetext{
${ }^{1}$ Event held over 3 to 5 days focusing on recording and evaluating a process, developing and redesigning a new process and implementing and reviewing some results from the event.
} 
Radnor et al. (2009) evaluated the Annual Reports 2007/08 referring to the evidence of Lean-related improvement activity through the corresponding website of 152 acute hospital Trusts in England. In their research they found that 53\% out of 80 Trusts cite the application of Lean, whereas $61 \%$ (i.e. 50 Trusts) have engaged with Lean only as 'productive ward'2, RIEs or few projects (with the remainder having carried out no activity or multi projects) (Radnor et al.. 2009). This finding supports the picture projected from the extant literature that many Hospital Trusts currently implementing Lean are undertaking small projects that do not form part of an integrated approach to service improvement ( Brandao de Souza, 2009; Radnor, 2010; Spear, 2005; Young and McCLean, 2008).

These RIEs or small isolated projects are often by default functionally orientated, i.e. focused upon one aspect of the patient pathway (the ward, pathology department, waiting lists etc.). The overall output thus may be 'point optimisation' akin to 'islands of optimisation' defined by Holweg and Pil (2001) whereby the affected function is run efficiently and effectively but all other aspects of the process or pathway either stay the same or, in some cases, have a negative impact on the wider system where process change in one place shifts the bottleneck and creates new problems in other parts of the pathway (Towill and Christopher 2005). They can be part of, but should not be the entire focus of, a Lean Programme.

Table 1: Example of Lean Implementations in Healthcare (based on the work of Guthrie, 2006; Radnor et al., 2006; Wysocki, 2004) around here

Much of the literature presents Lean as a fixed object, well-defined and designed, and then either implemented or not depending on the degree of resistance from the corresponding actors (e.g. Proudlove et al., 2008; Walley et al., 2001). The way in which Lean is adapted and negotiated in healthcare by various pressure groups aiming to achieve their own agendas has not been fully acknowledged in the literature.

Tragardh and Lindberg's (2004) and Papadopoulos and Merali’s (2008; 2009) studies of Lean implementation in Sweden and the UK respectively are among the few exceptions which study issues of adaptation and negotiation. They perceive Lean as resulting from negotiation and association between project members and underlying technologies. Our paper adds to this body of work by using ANT to explore the role of dynamic associations between heterogeneous actors (human and non-human entities) and the emergent networks in shaping

\footnotetext{
${ }^{2}$ The Productive Ward is a NHS initiative that presents a systematic way of making improvements on the ward through the application of the Lean technique 5S (a workplace discipline housekeeping approach through Sorting, Setting in Order, Sweeping and shining, Standardising and Sustaining).
} 
implementation and outcomes of a process improvement intervention drawing on Lean in a UK NHS trust. Its contribution to the OM field lies in its exposition of the use of ANT as a lens to understand the complexities in implementing operations management process improvement methodologies, particularly in contexts they were not designed to address. As Taylor and Taylor (2009) suggest, "there is increasing recognition of the benefit to be gained from exploring contemporary operations practice through alternative lenses and frameworks" (p. 1325). The next section introduces the key concepts of ANT.

\section{Actor-Network Theory}

In this section we outline the key features of ANT that make it particularly well-suited as a lens for exploring process interventions based on Lean thinking.

The characterisation of Lean as an integrated operational and socio-technical approach (Joosten et al., 2009) resonates with the conception of ANT as an approach for exploring interactions in socio-technical systems (Latour, 2005; Law and Callon, 1992).

Actor-Network Theory (Latour, 1987; 2005; Law and Callon 1992) characterises networks of interactions (associations) in socio-technical systems, how they are composed, their emergence over time, their construction and maintenance, how they compete with other networks and how they are made more durable over time. ANT takes a performative view; that is, phenomena do not exist in themselves but, rather, are created by actors in the process of continuing associations (Latour, 2005).

According to ANT, in order to grasp the emergence of the associations and the actors during change, human and non-human, social and technical factors should be considered and brought into the same analytical lens (Alcadipani and Hassard, 2010; Harrisson and Laberge, 2002; McLean and Hassard, 2004). The social aspects involve issues raised due to human stakeholders and their associations; the technical aspects have to do with bringing to the fore medical technologies, documents, workshops and processes, which are important during Lean projects.

One of the features of ANT that has inhibited its wider adoption is its use of specialised terminology (Table 2). The following definitions may be helpful for readers not acquainted with the vocabulary of ANT, and a more detailed account can be found in Latour (1987, 2005).

Actor: an actor can be defined as "any element which bends space around itself, makes other elements dependent upon itself and translates their will into the language of its own” (Callon 
and Latour, 1981: p. 286). ANT is peculiar in using "actor" to refer to both human and nonhuman entities. Human stakeholders, medical technologies, documents, workshops, and processes (non-human actors) are captured in the analysis.

Actor-network: an actor-network is a dynamic, actively shifting alliance of actors that generates and reproduces itself recursively, depending on the actions of the actors and actornetworks that it is constituted from. The associations between different actors and actornetworks cause the emergence of new identities and forms of organising; actors and organisations are the products and not the sources of organising (Latour, 2005).

Translation: Both human and non-human actors constantly emerge and associate with each other in actor-networks through a process of translation (Callon, 1986; Czarniawska, 2000; Czarniawska and Sevón, 1996). Specifically translation refers to the ways in which heterogeneous actors associate with each other and constitute, order and bring to an end actor-networks. This is comprised of four steps: problematisation, interessement, enrolment and mobilisation.

Problematisation: During problematisation, an actor makes an effort to make other actors subscribe to his/her own conceptions by demonstrating that (s)he has the right solutions to others' problems. The problem is refined in terms of solutions formed by the actor.

Obligatory Passage Point: The process of engaging others during problematisation is realised through the establishment of an Obligatory Passage Point (OPP), which comprises a number of specific conventions, rules, assumptions and ways of operating that have to be followed by other actors who wish to 'follow' the first actor.

Interessement: interessement follows problematisation - once the actors are engaged, an attempt is made to impose the identities and roles defined in the problematisation, thereby locking actors in the roles proposed for them, so that any already established networks may be replaced by the new network (Grint and Woolgar, 1997).

Enrolment: during enrolment, the actor-network emerges and actors yield to their defined roles (Singleton and Michael, 1993). 
Inscription: the roles assumed through enrolment have to be recorded into the actor-network through inscription. To promote inscription, specific inscription devices are used -“any setup, no matter what its size, nature and cost, that provides a visual display of any sort..." (Latour, 1987: 68), including the creation of texts and visual management tools.

Mobilisation: This is the final stage of translation: during mobilisation the proposed solution gains wider acceptance, and becomes taken-for-granted and black-boxed.

During organisational change, each of the different pressure groups that pursue their different agendas and interests - for instance, the management, the consultants, and the employees - may initiate translation to lead the change process towards their own favour. These translation attempts result in re-organising the emergence of the actor-networks and actors. Amongst these actors, there is a focal actor driving the process of engaging other actors to support a particular organisational transformation. The notion of the focal actor is useful, since, in cases where multiple actors are involved in the change process, the researcher usually selects a focal actor from whose perspective the translation process is observed. However, it should be noted that the focal actor may change during the translation process.

It should be noted that the notion of actor-network can be interpreted in different ways, depending on the level of analysis, complexity, or 'granularity' the researcher places in unpacking the phenomena under investigation, depending on the objectives (Munir and Jones, 2004).

Table 2: Actor-network Theory concepts and their definitions around here

In this paper we show the utilisation of ANT to study actions and events which have to do with the implementation of a management intervention based on Lean thinking. This intervention was labelled as an implementation of "Lean" within the case organisation, and we will refer to it as "Lean" in the account that follows, although in fact it only utilised a few of the techniques normally associated with Lean process design. In accordance with Latour (1986) we pay attention to the emergence of different actors and networks, the meanings they attribute to Lean; the ways they modify it, deflect it, add to it, or appropriate it as they seek to achieve their own goals, and the impact they have in the outcome of the deployment of Lean. This is because Lean cannot be regarded as a neutral device implemented without any objection. Rather, it is "both plastic enough to adapt to local needs and the constraints of the several parties employing [it], yet robust enough to maintain a common identity across sites” 
(Star and Griesemer, 1989: p. 393). This means that the implementation of Lean is far from automatic: it involves multiple negotiations between actors, definition and/or change of their identities and establishment or redistribution of their roles within the organisation (Munro, 1995). The proposed change for some of the stakeholders involved in the implementation process may be rejected, as it may not meet their expectations, needs or interests; conflicts and resistance may thus be manifested through associations and networks, which emerge during this process and evolve over time.

In our case analysis ANT is used:

- To identify the chains of actions and events implicated in the implementation of Lean over time;

- To show how diverse actors' and networks' actions and attribution of meanings are manifested, and determine the trajectory and success or failure of Lean deployment;

- To depict the emergence of the Lean as a phenomenon constructed, determined, deflected, modified, and appropriated by the associations between actors and their networks. This entails attending to both human (management, administrative, nursing and medical staff) and non-human (visual management tools -announcements, process maps, and communication boards) entities (Latour, 1986).

Although ANT shares common characteristics with the socio-technical systems theory (e.g. Trist and Murray, 1990, 1993; Trist et al., 1997) it is different in that it does not rely on large scale social forces to explain phenomena, it draws attention to the role of both human and non-human entities during the emergence of these phenomena, and regards all systems as comprised of both social and technical facets, "to the lowest levels of the workplace and the most subjective parts of human experience” (Latour, 1993: in Kaghan and Bowker, 2001: p. 265).

The use of ANT serves as a theoretical lens and approach (Latour, 2005) to study the assemblages of human and non-human entities and networks that come to the foreground during the implementation of process improvement methodologies. The practical challenge for the researcher is to present the case results in a narrative manner by identifying, describing, and explaining the relationships, associations, roles, and actions of the relevant actors (Akrich and Latour, 1992: p. 259): "the aim of the academic written analysis of a setting is to put on paper the text of what various the actors in the setting are doing to one another”. Following ANT studies (e.g. Berg, 1997; Callon, 1986; Latour, 1996; Mouritsen, 
2005; Mouritsen et al., 2002, 2009) the aim is not to present the actors/networks in a jargonlike manner; rather, it is to provide a comprehensive narrative de-scription - defined as a theorised reflexive discussion and explanation (Akrich and Latour, 1992; Latour, 2005) - of the actors and their networks in situ. Latour (2005) suggests that a good ANT account is "one that traces a network... is a narrative or a de-scription or a proposition where all the actors do something” (p. 128). It has to be noted that the notions of actor and actor-network can have different interpretations, depending on the level of analysis, complexity, or granularity placed by the researcher in the phenomena under investigation (Munir and Jones, 2004).

Hence, ANT provides an appropriate means for uncovering the emergence of actors and their associations, how these change over time and how they can be rendered temporarily stable, thereby assisting the deployment of Lean.

\section{Research methods}

The research for this paper follows the qualitative case study tradition (Lincoln and Guba, 1985; Silverman, 2001, Voss et al., 2002). The aim was to follow the appropriate actors and their associations, aiming to grasp the underlying dynamics in a complex process where a wide range of organisational phenomena within an organisational context take place. The focus of this study was on actions/events which were studied by deploying a variety of techniques when field material was gathered. The literature acknowledges that the complex and dynamic world situations in which organisations are embedded in call for less "hypothesis testing and more systematic observation to help managers deal with their actual problems” (Hayes, 2000: in Binder and Edwards, 2010: p. 233). In this vein, it is fruitful for the study of process improvement interventions to utilise theories that help to explain phenomena as they unfold over time, as well as the relationships between the participants who shape and are shaped by these phenomena (Binder and Edwards, 2010; Filippini, 1997). This makes explicit the need to deploy qualitative case study methods (Voss et al., 2002).

Data were collected mainly by interviewing (tape-recording) managers and staff, by analysing relevant written project material, and by conducting observations, according to the ANT approach which suggests the use of interviews, observations, and texts as the main sources of collecting data: "everything is data: from the first telephone call to a prospective interviewee, the first appointment with the advisor, the first connections made by a client on a grant proposal, the first launching of a search engine, the list of boxes to tick in a questionnaire” (Latour, 2005: p. 133). We viewed the data "not as objective evidence supporting or falsifying an assertion but as texts and text analogues, whose meanings, when 
read hermeneutically, can go beyond the original intentions and meanings attributed by their sources” (Sarker et al., 2006: p. 57).

Eighteen semi-structured interviews were conducted with staff, including board members, board and top executives, managers, biochemists and directors (Table 3). Interviews were audio-recorded and transcribed verbatim; their duration was 25 minutes on average. The range of people and actions/events during the implementation of Lean researched was wide. Staff were sampled according to their different posts and levels of seniority, as well as with respect to their involvement in the Lean projects.

Table 3: Number of conducted interviews and hours of observations around here

In addition to the interviews, researchers attended meetings, followed actors in their interactions, and talked informally with staff whenever possible over a period of six months. A research diary was kept to record the researchers' daily experience. Written documents were also collected, reviewed and analysed, thereby helping to track earlier actions and events that were of crucial importance in understanding the project.

Transcribed data were analysed using NVIVO Software for qualitative data analysis, and were assigned broad initial codes that were refined as research continued. Emergent themes were identified through reviewing field-notes and interview data, and supplementary codes emerged during this subsequent analysis. The emerging themes (see Table 4), referring, for instance, to the different interpretations of the process improvement intervention by different actors such as management, directors and staff and their networks, the meanings they attribute to Lean due to their interactions and negotiations while it was deployed and their scepticism regarding the deployment of the intervention, were further refined as the process continued, thus building the analysis incrementally.

\section{Implementing Lean in a unit of a UK hospital}

\subsection{Case overview: NHSCO hospital}

NHSCO is a hospital in the UK NHS, providing a wide range of services including a dedicated Accident and Emergency Unit, day case and routine surgery, and outpatient clinics for a range of services and specialisms. Our study was carried out while NHSCO was undertaking a major process revision to meet the Department of Health target of delivering an 18-week pathway from referral to treatment ( $\mathrm{DoH}, 2004)$. The Board articulated the need for rapid change to comply with this target, and the Chief Executive, familiar with process improvement from previous posts in the NHS, advocated the use of Lean principles. In this 
attempt, he co-opted the hospital Director of Operations, and a process improvement consultant from NHS, who agreed to be seconded to the hospital for two days per week to help in the interventions which were to be planned. Moreover, a Clinical Systems Engineer was employed at the hospital to assist in the interventions, and a Service Improvement Team (SIT) was created, with a common target -to improve current processes and conform to the 18-week target as set by the Department of Health.

Discussions with the various unit directors led to the choice of the Pathology Unit as the starting point for this exercise. The implementation of Lean in the Pathology Unit was aimed at improving turnaround times for all specimens' inpatients, outpatients and doctors, and enhancing staff morale and quality, as well as reducing waste and lowering costs, and enabling quicker clinical decisions and more efficient patient care.

\subsection{Implementing Lean in the Pathology unit}

The problems within the Pathology department were associated with the slow production of inpatient and outpatient test results. The point of specimen delivery was not manned and often there was a thirty minute delay before specimens were processed. The specimens were put into buckets so it was difficult to see which specimens arrived first, and time was needed to enter all the patient information and test request details onto the computers. Consequently, activities were duplicated and entailed wasteful movement and time spent searching for equipment and staff. The problem was compounded by the departmental layout and, additionally by demand which varied significantly by the hour, with a disproportionate volume of General Practitioner (GP) specimens arriving late in the afternoon. To address these problems, Lean was introduced with the expectation that it would have the impact summarised in Table 5.

Table 5: Anticipated Impact of Lean Implementation in Pathology Unit around here

As Figure 1 outlines, the implementation of Lean in the Pathology unit underwent three phases.

Figure 1: RIE Activities for the Pathology Unit implementation around here

\subsubsection{Phase 1: Pre-preparation for Rapid Improvement Event.}

The SIT set out to facilitate a Rapid Improvement Event (RIE), in which 18 participants (the SIT itself and 15 biochemists including the Pathology Director) would participate. In this 
attempt, the SIT was augmented by two external consultants from a private company that offered its expertise pro bono publico.

The SIT distributed a waste identification form (questionnaire) to the 15 biochemists to gather the data needed to track possible changes in specimen turnaround times, based on their opinions on

“...what is wasteful in our processes: what irritates; what they don't understand; what additional training can be put in place. All of those sort of questions are going out to the staff" (Biochemist).

The response rate was low (10\%); as a result, it could be argued that staff participation in this phase was not actually achieved. To trigger change discussions across the Unit and train staff for the forthcoming changes, the team conducted a one hour seminar on the introduction to Lean. Being imposed by the Pathology Director, the training was seen by the biochemists as a waste of time, and hence, problematisation failed in both attempts:

"The director said we must attend the event. Personally, and I think I can speak on behalf of all staff involved, I found it was such a hassle” (Biochemist).

However, the Director of Pathology was completely translated to Lean and clearly wanted to proceed with the changes despite the opposite opinion of the biochemists:

"I proposed to the hospital that this project should be considered for Lean and it was accepted... I didn't want particularly the hospital to invest in new staff; I want to run an efficient department...and basically when I began to understand what Lean was about I thought: ah it can solve both problems, that is, if we eliminate the waste of time specimens coming through, but also eliminate waste in process".

The perception of staff of the change to be initiated at this phase was as another management fad, transferred as a ready-made solution to their sub-units:

"I think he [the director of Pathology] had heard about the Lean process and he thought that was the best way thing to try in the lab just to...because it's the philosophy that is quite a good idea. So you hope that if you transfer it to a lab, it will work.” (Biochemist, Pathology Unit). 
It can be inferred that the SIT tried to use the training session and the questionnaires as an implicit way of communicating the improvements as the only solution to the problems of the Unit, thus ensuring that the interests of SIT to implement Lean are protected (inscription); in ANT terms, to 'translate' them into accepting Lean as OPP (Table 2), that is, the only way of dealing with the issues. The training session and questionnaires were important inscription devices, communicating the future changes and aimed at translating the Pathology staff (actors) into Lean.

The process of imposing the necessity of changes could not proceed further to lock the staff into the necessity of Lean and secure their consensus in the deployment process (interessement). The SIT had failed to problematise the biochemists effectively: a network comprised by those who were sceptical to changes and their interaction with medical instrumentation (the specimen reception, centrifuges, air-tubes, colours used in order to distinguish between different GP samples, buckets to store specimens and patient specimen forms which described the substance, department, type of test required and possible disease) had started to emerge, creating a stagnant way of working. This network perceived Lean as unnecessary and unable to deal with changes. This unwillingness reflected an entrenched way of working and was manifested in their unwillingness to attend the seminar or respond to the questionnaire. However, in a different vein, they did entertain the possibility that Lean might be a vehicle for voicing complaints to managers about the insufficient human resources and equipment.

5.2.2 Phase 2: Rapid Improvement Event Days 1 and 2. Despite the unsuccessful first attempt to impose Lean as a solution (that is, problematisation), the SIT proceeded to the second stage of the Lean deployment process, which was to conduct the RIE.

The Chief Executive and Director of Operations (SIT actors) expressed their ownership and support and acted as facilitators, stressing its importance for Pathology and encouraging staff to proceed to the changes during the RIE. Their action on behalf of the SIT network to promote Lean reflected the fact that they were persuaded about Lean as the only solution to the problems of the Unit (i.e. in ANT terms [Table 2]), had undergone all stages of translation; that is, problematisation, interessement, enrolment, and were hence mobilised to Lean). During the workshop, current process state maps were created and data were collected by observing staff. Data showed the increasing daily demand by hour and revealed that action should be taken with regard to the specimen turnaround time. The participants developed a future process state map and decided to reorganise the unit spatially, man the reception, and reschedule deliveries for better process. The process maps, in ANT terms (Table 2), were 
important inscription devices, as they communicated the translation suggested by SIT and Lean and were ensuring that the implementation will take place (inscription). They allowed actors to assess activities that would take place through the use of writing, and intervene in the following months from a different time (i.e. the time the RIE took place). Finally, they would render more visible the processes and activities that were taking place in the Pathology Unit.

During days 1 and 2, the researchers observed a breach in the relationship between staff and SIT. The latter were not willing to proceed to changes, according to their views implicitly expressed in the previous stage. On the other hand, the target of SIT and management was to use Lean to reduce waiting times. Hence, despite the aim of biochemists to use Lean as a way of voicing complaints for inefficiencies in human resources and equipment, any investment on medical equipment or staff was not on their agenda. They perceived Lean as a 'quick and dirty' method of bringing turnaround times and associated costs down, but more importantly, to deal with the staff complaints:

“I would say: 'It worked for us', and people stop moaning at me:

'there is too much work'”' (Director of Pathology Unit).

5.2.3: Phase 3: Rapid Improvement Event Days 3 and 4 and post-RIE events. The Pathology staff decided to adopt a 'trial and error' approach, by drawing a future process map, formulating a project plan and proceeding to the further implementation of the changes. This was because of the projected benefits that were presented to them showing the reduction in overtime work to prepare the samples for testing: now, their previous perceptions of Lean as a negotiation tool were replaced by their interessement in improving the efficiency of the process and suggesting 'bottom-up' changes:

“they were sort of saying to us: 'Oh we have an idea' and

suggested it. That is good because they did not just initially

try to get us to do it, because obviously it's just things that say

'oh do this' and is not physically possible to do that because

of...so it was quite nice that they listened to us" (Biochemist)

The suggested changes identified on the future process map included, for instance, different uses for centrifuges, air-tubes and colours, and the movement of the specimen reception in another area to decrease the noise occurring in the specimen reception and allow specimens to arrive more rapidly and to be handled quicker. Moreover, the specimen forms 
for booking in specimens were to be reformatted for easier processing, improving the time to recognise the sender (hospital unit) and test needed. Therefore, staff, considering the tangible benefits that Lean would bring, accepted the idea of trying the proposed changes without any further scepticism, even if this meant that they would alter the practices they had followed for over 25 years; hence, they started to become part of the SIT network. As a biochemist observed:

"...they came down, two days after we had made our first changes...that was excellent, I don't think we've seen in Pathology... I have never shook hands with him [the Chief Executive] before... and I think that is a great boost to the people that were involved and all the staff that are working in there."

In ANT terms (Table 2) a Lean-network started to emerge (actor-network), consisting of SIT and the staff network. The latter, being previously sceptical to Lean, was persuaded to accept the Lean network to talk on their behalf and become gradually black-boxed (translation- mobilisation stage). The Lean network was supposed to implement changes according to the project planning created.

However, the Lean-favouring network, being a dynamic structure, did not remain stable. The Chief Executive was appointed in another NHS position. Additionally, the Director of Operations needed the support and approval of the Chief Executive, since there was no formal Lean strategy approved by NHSCO Board. The implementation was stalled and the staff network started to shift back to the old system of booking and testing specimens. Using the old ways of working, which according to the staff were not efficient but wellestablished, they succeeded in shifting other staff members (actors) back; these members seemed to like the idea of going back to the 'old days'. For at least two months after the end of the RIE, the Unit was in a chaotic stage:

“...I wasn't sure what I was doing anymore. I was so used to be in a small space... and doing things differently...when I came in...The first week we changed it was a nightmare; everybody was all over the place” (Biochemist).

As the pro-Lean network started to shrink, a new Chief Executive was appointed. He believed that this network should be revived and implementation should be resumed as he viewed Lean as a way of bringing down costs. As a result, he intervened and promised more resources to staff through future investments in new equipment. This was a new solution (a 
new OPP) and a new process began (translation). As part of his timely intervention, the Lean network started to revive. The new Chief Executive's presence was a means to persuade staff to embrace, understand and accept -be translated into - Lean:

"I have never shook hands with him [the Chief Executive] before... and I don't think he said 'yes' to come and look in Pathology as much as he did after we did that...and I think that is a great boost to the people that were involved and all the staff that are working in there. It also makes the rest of the staff thinking: 'Oh what are they doing? They have the Chief Executive come down to see them'. So I think that was...that was really good to get that. And that makes you feel as so you are doing something worthwhile" (Biochemist).

Given the visible support of the Chief Executive, the Director of Operations and the Pathology director began to support the implementation in terms of time and effort. They introduced visual management tools to help staff adapt to changes, and promised resources in terms of equipment, which would be decided after an audit was to take place. Performance achievement sheets were displayed around the department, showing the drop in waiting times, and signs were placed around the department to assist staff in becoming accustomed to Lean. There was constant reinforcement in place for mobilising actors into Lean:

"There were constant slip-backs to the old way of doing things and again, having the external people here and one person supervising were instrumental in preventing that constantly saying: 'no you are not gonna slip back to your old routines. This is the way to do it. We've got to try it; we've got the hurdle to go over; it will take a while to get used to it but trust'... and essentially the words were: 'we've had the experts look at this. Let's do what they tell us to... we've got to give it a try'. And that is how we solved it, you know. These people know what they are doing, they've looked at it, studied the timing: it should work" (Director of Pathology).

Opposing staff realised the importance of the tangible benefits of the project and the resources they would received and, subsequently translated this to Lean. 
"Over the last few weeks, [staff] minds have just been changed on the fact that 'hang on, its working better than it was before, everything is going through quicker"' (Haematologist).

Other, still sceptical, staff followed through mimicry and indirect enforcement, as they understood that the only way not to be isolated was to adopt and adapt to the changes:

"the majority of people were OK; some was still against, but they are all coming round...they get used to the idea that it is happening; and if you're against these things, its going to happen regardless of what you are thinking, so the best way to deal is get on with it and you'll find it a lot easier" (Biochemist).

Hence, the staff network adapted to changes, with its actors gradually becoming translated into the Lean network. This was achieved by the Lean actor-network, which succeeded in persuading staff to embrace, understand and accept - (be translated into) Lean.

“It wasn't perfect, and but major things will never be perfect, but it was considerably better; not only that, but also ...the role that we had enabled us to actually implement additional Lean things that by now we've got, the understanding of the process, eliminate waste, waste can be time-waiting somewhere" (Director of Pathology).

The Pathology Unit is due to get new technological equipment, a demand expressed by staff during the previous phases of the Lean implementation. NHSCO is currently auditing the needs of Pathology. The review aims to evaluate whether the Unit needs refurbishment in a capital expenditure of $£ 100,000-150,000$. Hence, the Lean implementation journey in the Pathology Unit is still ongoing.

The post-RIE progression of events is depicted in Figure 2.

Figure 2: Post RIE progression of events over time around here

The emergent themes from the case study are presented in Table 4.

Table 4: Emergent themes and supporting literature around here.

\section{Discussion}

In the previous section, we followed the actors in their interactions (e.g. Latour, 2005) and showed how their dynamics, which were manifested through the creation of the Lean actor- 
network, shaped the identities and behaviours of actors that participated in the implementation, contributing to the successful trajectory and outcome of Lean. The trajectory shows the difficult start (questionnaires and seminar not yielding expected engagement) of the initiative with the failure to engage biochemists in the problematisation created by the SIT. The SIT network and the biochemist network (of the individuals and their equipment) were distant from each other. The RIE afforded a space where positions could be adjusted, and the problematisation was moved down to the level of participating in the workshop and benefiting from the projected future Lean benefits. This resulted in a period of successful interessement and enrolment of the biochemists into the development of a future-state map and a process improvement plan (with OPPs furnished by the RIE). However the change was not embedded in the organisation before key actors withdrew - i.e. there was a failure to mobilise fully biochemists, the pro-change SIT network disintegrated and the retrograde network of biochemists started to emerge. The situation was redeemed by the arrival of the new CEO who formulated a different problematisation which enabled the re-engagement of the biochemists with the SIT network.

The empirical findings of the study have shown the way in which the heterogeneous actors associated with each other during the Lean project and how their dynamics were manifested through networks during the implementation process. The ANT lens enables the articulation of the richness of the context of the human and non-human actors in the process. The translation of the staff network into Lean emerged through the dynamic process of actors joining the Lean actor-network: no single actor or incentive or directive was responsible for this shift. The recruitment and mobilisation of actors was realised through their interactions with the evolving actor-network which comprised human actors and non-human entities (e.g. the visual displays as inscription devices). The use of the visual charts displaying the performance created support to the communication process, thus allowing the OPP to be achieved.

Throughout the implementation process, there were various attempts by the SIT to make Lean principles work in practice and align them with the existing routines. However, in contrast to previous literature (e.g. Esain et al., 2008; Proudlove et al., 2008; Radnor, 2010; Walley et al., 2001) the actors involved were not passive receivers of Lean; rather, their actions and translations determined its trajectory and outcome. The process involved an ongoing translation, in which the new idea or model (in this case, the Lean project and its benefits) is aimed to be modified and integrated with existing traditions (Czarniawska, 2002). The implementation of Lean involved a process of negotiations, articulations and conflicts, as 
managers and staff "had their own 'truths' or, more sensibly [logically], 'rationales' regarding the hospital and its future” (Dent, 2003: p. 123).

Our case study analysis demonstrates the centrality of translation to the deployment of the Lean intervention. Translation constitutes a mechanism for elucidating the way allies are engaged to follow the specific goals of Lean as determined by the SIT and Lean network than others in the implementation process. It also explains the successful trajectory of Lean through the progressive strengthening of the Lean network which occurs as more human and non-human actors/allies are incorporated in the network. Ultimately the mobilisation of the Lean actor-network is realised through the construction of identities prone to Lean innovative behaviour and the capability for sustained performance improvement. This acquires the association of actors with various inscription devices (e.g. the process maps) that will enable the emergence of a solid and sound appearance of the Lean network, i.e. its ability to become robust and irreversible (Monteiro, 2000) since it will behave as "one actor" with the aim of translating sceptical and opposing actors towards the acceptance of Lean and transform Lean into "black-box", which will not subsequently be questioned for at least some time (Latour and Woolgar, 1979: p. 241-243).

The "trials of strength" between actors and networks can take place anytime (Latour, 1987: p. 74). To be victorious, the Lean actor-network must battle against 'counteractors' and defeat their 'antiprogrammes'; that is, old working practices (Alcouffe et al., 2008: p. 4). In this case, battles took place with other members of the network and the competing staff network, as well as with non-human actors (e.g. the material manifestations of the proposed process changes) and inscription devices (e.g. the process maps, and the questionnaire). These battles acted as negotiations that modified Lean. Thus, Lean was not implemented as a fixed object. Instead, it emerged as an outcome of negotiations and translation that change both the translator (managers and SIT, who had to provide more resources, as well as staff, who agreed or partially disagreed to deploy Lean) and what is being translated (Lean) (Czarniawska, 2002), and helped sustain the network in an acceptable way for all the actors that constituted it.

We followed the journey from the "top level" decision to use Lean through to the resulting process improvement implementation. Our analysis generated insights that may be of use to management in the orchestration of process improvement programmes. The use of the ANT lens

- revealed the turbulent dynamics associated with the process change, and 
- allowed the characterisation of "turning points" where apparently incompatible networks could engage, and

- highlighted devices that enable disparate groups (actor-networks) to engage with each other.

These devices include

- articulating the proposition in terms that represent solutions to problems that matter to the constituency they wish to engage (problematisation)

- creation of a "neutral” space for engagement (in our case the RIE) where actors can exercise their competence within a set of conventions (i.e. OPPs in ANT terminology)

- the co-creation by the actors of objects that demarcate their engagement (inscription devices - in our case, for instance, the future maps and charts)

\section{Conclusion}

In this paper, we set out to demonstrate the utility of the ANT lens for exploring the dynamics in the implementation of a process improvement methodology in a public sector setting where the process intervention is contested. A rich qualitative study was conducted in the Pathology Unit of a UK NHS Trust using ANT as the theoretical lens for tracking the emergence and transformation of networks of individuals over the course of a management intervention to promote "Lean thinking" for performance improvements. The case study revealed the complex and emergent landscape of actors and agendas that come to the foreground during the intervention and the emerging challenges stemming from the ordered, rational engineering basis for Lean and the messy and sometimes meandering trajectory of its implementation, as the organisation shifts from entrenched routines to a new process organisation. Therefore, the contribution of the paper lies in the application of ANT as a lens through which a number of implications related to the deployment of interventions based on Lean thinking can be explored, which are not apparent within the current Lean or process improvement literature (e.g. Brandao de Souza, 2009; Esain et al., 2008; Holweg and Pil, 2001; Proudlove et al., 2008; Radnor, 2010; Walley et al., 2001). Moreover, this paper complements current literature on ANT focusing on Healthcare (e.g. Nicolini, 2009; Tragardh and Lindberg, 2004) by showing its application in the complex setting of implementing a process improvement methodology in a UK NHS Trust.

The paper highlights the role of orchestrating the views and agendas of the various actors in a network (actor-network) to create spaces and choice points that facilitate a shift from entrenched routines to new process organisation. These spaces and choice points change 
over the time of the project; and different actors, views, and resources come into play at different times over the lifetime of the intervention. However, all require the human actor to make a choice and to commit to a course of action and conventions of practice that are coherent with regard to the network that (s)he enters. Commitment may contribute to temporal stability of the emerging network.

Hence, the key contribution of this paper is to bring to the foreground the fluid and occasionally turbulent organisational reality that underpins the implementation of process or operations improvement interventions in complex environments. Understanding the dynamics and mechanisms that underpin the emergence and transformation of the networks may enable managers to develop more effective strategies for orchestrating change in such contexts.

\section{References}

Akrich, M. and Latour, B. (1992), "A Summary of a Convenient Vocabulary for the Semiotics of Human and Nonhuman Assemblies", in Bijker, W. and Law, J. (Eds), Shaping Technology/Building Society, MIT Press, Cambridge, pp. 259-64.

Alcadipani, R. and Hassard, J. (2010), “Actor-network Theory, organizations and critique: towards a politics of organizing”, Organization, Vol. 17 No. 4, pp. 419-35.

Alcouffe, S., Berland, N. and Levant, Y. (2008), "Actor-networks and the diffusion of management accounting innovations: A comparative study”, Management Accounting Research, Vo. 19, pp. 117.

Berg, M. (1997), Rationalising medical work, MIT Press, Cambridge.

Bevir, M. and Richards, D. (2009), "Decentring policy networks: a theoretical agenda”, Public Administration, Vol. 87 No. 1, pp. 3-14.

Binder, M. and Edwards, J. S. (2010), "Using grounded theory method for theory building in operations management research. A study on inter-firm relationship governance", International Journal of Operations \& Production Management, Vol. 30 No. 3, pp. 232-59.

Brandao de Souza, L. (2009), "Trends and approaches in Lean healthcare," Leadership in Health Services, Vol. 22 No. 2, pp. 121-39.

Callon, M. (1986), "Some elements in sociology of translation: domestication of the scallops and fishermen of St. Brieuc Bay”, in Law, J. (Ed), Power, action and belief, Routledge, London, pp. 196-233.

Callon, M., and Latour, B. (1981), "Unscrewing the Big Leviathan: How Actors Macro-Structure Reality and How Sociologist Help Them To Do So”, in Knorr-Cetina, K.; Cicouvel, A.V. (Eds) Advances in Social Theory and Methodology: Towards an Integration of Micro and MacroSociology, London: Routledge, Boston, MA.

Czarniawska, B., and Sévon, G. (Eds.) (2005), Global Ideas: How Ideas, Objects and Practices Travel in the Global Economy, Liber \& Copenhagen Business School Press, Malmö.

Czarniawska, B. (1997), Narrating the Organization: Dramas of Institutional Identity, University of Chicago Press, Chicago and London.

Czarniawska, B. (2000), “Organisational translations”, in Kalthoff, H., Rottenburg, R. and Wagener, H. (Eds), Facts and figures. Economic representations and practices, Metropolis, Marburg, pp. 117-42. 
Czarniawska, B. (2002), "Remembering while forgetting: The role of automorphism in city management in Warsaw”, Public Administration Review, Vol. 62 No. 2, pp. 163-73.

Czarniawska, B. and Sevón, G. (1996), “Introduction”, in Czarniawska, B. and Sevón, G. (Eds), Translating Organisational Change, Walter de Gruyter \& Co, Berlin, pp. 1-12).

Dent, M. (2003), "Managing doctors and saving a hospital: Irony, rhetoric and actor networks," Organisation, Vol. 10 No. 1, 107-27.

Department of Health (DH) (2004), The NHS Improvement Plan: Putting People at the heart of public services. London: HMSO.

Esain, A., Williams, S. and Massey, L. (2008), "Combining Planned and Emergent Change in a Healthcare Lean Transformation”, Public Money and Management, Special Issue on Lean in public services, Vol. 28 No. 1, pp. 21-6.

Filippini, R. (1997), "Operations management research: some reflection on evolution, models and empirical studies in OM”, International Journal of Operations \& Production Management, Vol. 17, No.7, pp. 655-670.

Greenhalgh, T., Robert, G., Macfarlane, F., Bate, R. and Kyriakidou, O. (2004), "Diffusion of innovation in service organisations: Systematic review and recommendations", Milbank Science Quarterly, Vol. 82 No. 4, pp. 581-629.

Grint, K. and Woolgar, S. (1997), The Machine at Work - Technology, Work and Organisation, Polity Press, Cambridge.

Guthrie, J. (2006), The Joys of a Health Service Driven by Toyota, Financial Times, 22 June.

Harrisson, D. and Laberge, M. (2002), "Innovation, identities and resistance: The social construction of innovation”, Journal of Management Studies, Vol. 39 No. 4, pp. 497-521.

Hayes, R. H. (2000), “Toward a 'new architecture' for POM”, Production and Operations Management, Vol. 9 No. 2, pp. 105-10.

Hines, P., Holweg, M. and Rich, N. (2004), "Learning to evolve: a review of contemporary Lean thinking”, International Journal of Operations and Production Management, Vol. 24 No. 10, pp. 994-1011.

Hines, P., Found, P. and Harrison, R. (2008), "Staying Lean: thriving, not just surviving”, Working paper, Lean Enterprise Research Centre, Cardiff University, Cardiff.

Holweg, M. and Pil, F. (2001), "Successful build-to-order strategies start with the customer", Sloan Management Review, Vol. 43 No. 1, pp. 74-83.

Joosten, T., Bongers, I. and Jansssen, R. (2009), “Application of Lean thinking to health care: issues and observations”, International Journal for Quality in Health Care, Vol. 21 No. 5, pp. 341-47.

Kaghan, W. N., and Bowker, G. C. (2001), "Out of machine age?: complexity, sociotechnical systems and actor network theory.” Journal of Engineering and Technology Management, 18, pp. 253269.

Latour, B. (1986), “The powers of association”, in Law, J. (Ed), Power, Action and Belief. A New Sociology of Knowledge? Routledge and Kegan Paul, London, pp. 264-80.

Latour, B. (1987), Science in Action: How to Follow Scientists and Engineers through Society, Open University Press, Milton Keynes.

Latour, B. (1996), Aramis, or the love of technology, Harvard University Press, Cambridge Mass.

Latour, B. (2005), Reassembling the social: an introduction to Actor-network-Theory, Oxford University Press, Oxford, New York.

Latour, B. and Woolgar, S. (1979), Laboratory Life: The Social Construction of Scientific Facts, Sage, London. 
Law, J. (1992), "Notes on the theory of the actor network: ordering, strategy and heterogeneity", Systems Practice, Vol. 5 No. 4, pp. 379-93.

Law, J. and Callon, M. (1992), "The Life and Death of an Aircraft: A Network Analysis of Technical Change”, in Bijker, W.E. and Law, J. (Eds), Shaping Technology/Building Society: Studies in Sociotechnical Change, MIT Press, Cambridge, MA, pp. 21-52.

Law, J. and Hassard, J. (1999), Actor-network Theory and after, Blackwell Publishing.

Lincoln, Y. S. and Guba, E. G. (1985), Naturalistic Inquiry, Sage, Newbury Park, CA.

McLean, C. and Hassard, J. (2004), "Symmetrical Absence/Symmetrical Absurdity: Critical Notes on the Production of Actor-network Accounts", Journal of Management Studies, Vol. 41 No. 3, pp. 493-519.

Monteiro, E. (2000), “Actor-network theory”, in Ciborra, C. (Ed), From Control to Drift. The Dynamics of Corporate Information Infrastructure, Oxford University Press, Oxford, pp. 71-83.

Mouritsen, J. (2005), "Beyond accounting change: Design and mobilisation of management control systems”, Journal of Accounting and Organisational Change, Vol. 1 No. 1, pp. 97-113.

Mouritsen, J., Larsen, H. T. and Hansen, A. (2002), "Be critical! Critique and naivete - Californian and French connections in critical Scandinavian accounting research", Critical Perspectives on Accounting, Vol. 13 No. 4, pp. 497-513.

Mouritsen, J., Hansen, A. and Hansen, C. (2009), "Short and long translations: Management accounting calculations and innovation management", Accounting, Organizations and Society Vol. 34 No 6/7, pp. 738-54.

Munir, K.A. and Jones, M. (2004), "Discontinuity and after: The social dynamics of technology evolution and dominance”, Organization Studies, Vol. 25 No. 4, pp. 561-81.

Munro, R. (1995), "Governing the new province of quality: Autonomy, accounting and the dissemination of accountability", in Wilkinson, A. and Willmott, H. (Eds), Making Quality Critical: New Perspectives on Organizational Change, Routledge, London, pp. 127-55.

Nicolini, D. (2009), "Medical Innovation as a Process of translation: a case from the field of Telemedicine", British Journal of Management, In press, DOI: 10.1111/j.14678551.2008.00627.x

Papadopoulos, T. and Merali, Y. (2009), "Stakeholder dynamics during process innovation implementation in healthcare: Lean Thinking in a hospital of UK National Health Service", International Journal of Healthcare Technology \& Management, Vol. 10 No. 4/5, pp. 303-24.

Papadopoulos, T. and Merali, Y. (2008), "Stakeholder Network Dynamics and Emergent Trajectories of Lean Implementation Projects: A Study in the UK National Health Service”, Public Money and Management, Special issue on Lean in public services, Vol. 28 No. 1, pp. 41-49.

Proudlove, N., Moxham, C. and Boaden, R. (2008), "Lessons for Lean in Healthcare From Using Six Sigma in the NHS”, Public Money and Management, Special Issue on Lean in Public Services, Vol. 28 No. 1, pp. 27-34.

Radnor, Z. J. (2010), "Review of Business Process Improvement Methodologies in Public Services”, Advanced Institute of Management, London, May 2010.

Radnor, Z. and Boaden, R. (2008), “Does Lean Enhance Public Services? Editorial”, Public Money and Management, Special issue on Lean in Public Services, Vol. 28, pp. 3-6.

Radnor, Z. J., Davies, R. and Burgess, N. (2009), How much Lean are English hospitals implementing? National Health Executive, 60-62, Sep/Oct09, at: http://www2.warwick.ac.uk/fac/soc/wbs/projects/slim/pub/nhe how much lean are english hos pitals implementing .pdf, accessed 20/03/2010.

Radnor, Z., Walley, P., Stephens, A. and Bucci, G., (2006), "Evaluation of the Lean approach to business management and its use in the public sector", Government Social Research. 
Sarker, S., Sarker, S., and Sidorova, A. (2006), "Actor-Networks and Business Process Change Failure: An Interpretive Case Study,” Journal of Management Information Systems, Vol.23, No.1, pp. 51-86.

Savitz, L., Kaluzny, A. and Kelly, D. (2000), "A life-cycle model of continuous clinical process innovation”, Journal of Healthcare Management, Vol. 45 No. 5, pp. 307-16.

Shah, R. and Ward, P.T. (2003), "Lean manufacturing: context, practice bundles, and performance”, Journal of Operations Management, Vol. 21 No. 2, pp. 129-49.

Shah, R. and Ward, P. T. (2007), “Defining and developing measures of Lean production”, Journal of Operations Management, Vol. 25, pp. 785-805.

Silverman, D. (2001), Interpreting Qualitative Data: Methods for Analysing Talk, Text and Interaction, Sage, London.

Silvester, K., Lendon, R., Bevan, H., Steyn, R. and Walley, P. (2004), "Reducing waiting times in the NHS: is lack of capacity the problem?” Clinician in Management, Vol. 12 No. 3, pp. 105-11.

Singleton, V. and Michael, M. (1993), “Actor-networks and Ambivalence: General Practitioners in the UK Cervical Screening Programme”, Social Studies of Science, Vol. 23, pp. 227-64.

Spear, S. J. (2005), "Fixing health from the inside, today”, Harvard Business Review, Vol. 83 No. 9, pp. 78-91.

Spear, S. and Bowen, H. K. (1999), “Decoding the DNA of the Toyota Production System”, Harvard Business Review, September-October, pp. 97-106.

Star, S. L. and Griesemer, J. R. (1989), "Institutional ecology, 'translations' and boundary objects: Amateurs and professionals in Berkeley's Museum of Vertebrate Zoology 1907-39”, Social Studies of Science, Vol. 19 No. 3, pp. 387-420.

Taylor, A. and Taylor, M. (2009), "Operations management research: contemporary themes, trends and potential future directions", International Journal of Operations and Production Management, Vol. 29 No. 12, pp. 1316-340.

Towill, D. R. and Christopher, M. (2005), "An evolutionary approach to the architecture of effective healthcare delivery systems”, Journal of Health Organisation and Management, Vol. 19 No. 2, pp. 130-47.

Tragardh, B. and Lindberg, K. (2004), "Curing a meagre health care system by Lean methods-translating 'chains of care' in the Swedish health care sector", International Journal of Public Health, Vol. 19 No. 4, pp. 383-98.

Trist, E. and Murray, H. (Eds.) (1990), The Social Engagement of Social Science: A Tavistock Anthology, The Social Psychological Perspective, Vol. I. University of Pennsylvania Press, Philadelphia, PA.

Trist, E., and Murray, H. (Eds.) (1993), The Social Engagement of Social Science: A Tavistock Anthology, The Socio-technical Perspective, Vol. II. University of Pennsylvania Press, Philadelphia, PA.

Trist, E., Emery, F., and Murray, H. (Eds.) (1997), The Social Engagement of Social Science: A Tavistock Anthology, The Socio-ecological Perspective, Vol. III. University of Pennsylvania Press, Philadelphia. PA.

Voss, C., Tsikriktsis, N. and Frohlich, M. (2002) “Case Research in Operations Management”, International Journal of Operations and Production Management, Vol. 22 No. 2, pp. 195-219.

Walley P., Watt A., Davies C., Huang, A. and Ma, K. (2001), "A study of demand for emergency access health services in two UK health regions”, Working Paper, Warwick Business School, Warwick.

Womack, J. P., Jones, D. T., and Roos, D. (1990). The machine that changed the world. Rawson: Macmillan Press. 
Womack, J.P. and Jones, D.T. (1996), "Lean Thinking”, Book Review, Financial Times, 30th September.

Wysocki, B. (2004), "How Toyota's production techniques are applied to hospitals", Wall Street Journal, 9th April.

Young, T. P. and McCLean, S. I. (2008), "A critical look at Lean Thinking in healthcare", Quality \& Safety in Health Care, Vol. 17, pp. 382-86. 